\begin{tabular}{|l|c|c|c|l|l|}
\hline \multirow{2}{*}{$\mathcal{2}$} & P H P & \multicolumn{1}{|c|}{12639} & \multirow{2}{*}{ WILEY } & Dispatch: 27.9.16 & CE: Madhumitha R \\
\cline { 2 - 3 } \cline { 5 - 5 } & Journal Code & Manuscript No. & & No. of pages: 5 & PE: Muthamilselvi S. \\
\hline
\end{tabular}

\title{
Q I Bioluminescent Enzymatic Assay as a Tool for Studying Antioxidant Activity and Toxicity of Bioactive Compounds ${ }^{\dagger}$
}

\author{
Nadezhda S. Kudryasheva ${ }^{\star 1,2}$, Ekaterina S. Kovel ${ }^{1,2}$, Anna S. Sachkova ${ }^{3}$, Anna A. Vorobeva ${ }^{3}$, \\ 3 Viktoriya G. Isakova ${ }^{4}$ and Grigoriy N. Churilov ${ }^{4}$ \\ ${ }^{1}$ Institute of Biophysics SB RAS, Krasnoyarsk, Russia \\ ${ }^{2}$ Siberian Federal University, Krasnoyarsk, Russia \\ ${ }^{3}$ National Research Tomsk Polytechnic University, Tomsk, Russia \\ $4{ }^{4}$ Institute of Physics SB RAS, Krasnoyarsk, Russia \\ Received 17 July 2016, accepted 5 August 2016, DOI: 10.1111/php.12639
}

\section{ABSTRACT}

A bioluminescent assay based on a system of coupled enzymatic reactions catalyzed by bacterial luciferase and NADH: FMN-oxidoreductase was developed to monitor toxicity and antioxidant activity of bioactive compounds. The assay enables studying toxic effects at the level of biomolecules and physicochemical processes, as well as determining the toxicity of general and oxidative types. Toxic and detoxifying effects of bioactive compounds were studied. Fullerenols, perspective pharmaceutical agents, nanosized particles, water-soluble polyhydroxylated fullerene-60 derivatives were chosen as bioactive compounds. Two homologous fullerenols with different number and type of substituents, $\mathrm{C}_{60} \mathrm{O}_{2-4}(\mathrm{OH})_{20-24}$ and $\mathrm{Fe}_{0.5} \mathrm{C}_{60}(\mathrm{OH}){ }_{x} \mathrm{O}_{y}(x+y=40-42)$, were used. They suppressed bioluminescent intensity at concentrations $>0.01 \mathrm{~g} \mathrm{~L}^{-1}$ and $>0.001 \mathrm{~g} \mathrm{~L}^{-1}$ for $\mathrm{C}_{60} \mathrm{O}_{2-4}(\mathrm{OH})_{20-24}$ and $\mathrm{Fe}_{0.5} \mathrm{C}_{60}(\mathrm{OH})_{\mathrm{x}} \mathrm{O}_{\mathrm{y}}$, respectively; hence, a lower toxicity of $\mathrm{C}_{60} \mathrm{O}_{2-4}(\mathrm{OH})_{20-24}$ was demonstrated. Antioxidant activity of fullerenols was studied in model solutions of organic and inorganic oxidizers; changes in toxicities of general and oxidative type were determined; detoxification coefficients were calculated. Fullerenol $\mathrm{C}_{60} \mathrm{O}_{2-4}(\mathrm{OH})_{20-24}$ revealed higher antioxidant ability at concentrations $10^{-17}-10^{-5} \mathrm{~g} \mathrm{~L}^{-1}$. The difference in the toxicity and antioxidant activity of fullerenols was explained through their electron donor/acceptor properties and different catalytic activity. Principles of bioluminescent enzyme assay application for evaluating the toxic effect and antioxidant activity of bioactive compounds were summarized.

\section{INTRODUCTION}

Fullerenols are nanosized structures, water-soluble polyhydroxylated derivatives of fullerenes (an allotropic form of carbon), bioactive compounds and perspective pharmaceutical agents. Chemical structure of a representative of fullerenol group, $\mathrm{C}_{60}(\mathrm{OH})_{\mathrm{x}}$, is presented in Scheme 1.

*Corresponding author email: n_qdr@yahoo.com (N. S. Kudryasheva)

$\dagger$ This article is a part of the Special Issue devoted to various aspects of basic and applied research on Bioluminescence.

(C) 2016 The American Society of Photobiology
Fullerenols are electron deficient structures, and this property makes them useful as efficient catalyzers in biochemical reactions. Fullerenols are amphiphilic structures: Hydroxyl groups provide them with aqueous solubility, while the fragments of fullerene skeleton - with affinity to hydrophobic enzymatic fragments and lipid structures of cellular membranes $(1,2)$. The aqueous solubility of fullerenols depends on the amount of hydroxyl groups (3).

Being bioactive compounds, fullerenols can produce either toxic or activating effect (3-6). The biological activity of a series of fullerenols $\mathrm{C}_{60}(\mathrm{OH})_{12-14}, \mathrm{C}_{60}(\mathrm{OH})_{18-24}, \mathrm{C}_{60}(\mathrm{OH})_{30-38}$ was studied by Eropkin and coworkers (3). Fullerenols $\mathrm{C}_{60}(\mathrm{OH})_{18-24}$ have revealed maximal biological activity $(4,7,8)$. Fullerenols demonstrated antioxidant activity, neutralizing reactive oxygen and nitrogen species $(5,8,9)$, correcting neurological diseases $(4,5,9,10)$, as well as functioning as radioprotectors (9) or antitumor agents (6).

The bioluminescence assays based on luminous marine bacteria or their enzymes are proper candidates for monitoring the toxicity and antioxidant activity of fullerenols. Bioluminescence of marine bacteria is known to be sensitive to toxic compounds; this is why the bacteria have been widely used as a bioassay for several decades (11-15). The physiological parameter being tested here is luminescence intensity; it can be easily measured instrumentally. Suppression of the bioluminescent intensity evaluates toxicity of aqueous solutions, while the bioluminescence activation serves as an evidence of improving the luminescent physiological function. The last decade has seen the application of luminous bacteria to monitor biological effects of low-dose ionizing radiation (16-18). Due to simplicity and high rates of test procedure, bacteria-based bioluminescent assay makes it possible to simultaneously analyze many test samples, and, therefore, perform a proper statistical treatment of low-dose effects.

Bacterial bioluminescent assays can be based on biological systems of different complexity-bacteria or their enzymes, providing comparison of toxic effects on microorganisms or their enzymatic reactions (12,16-20). These assays allow for studying the mechanisms of toxic effects at cellular or molecular levels, respectively. The possibility of studying the physicochemical and molecular mechanisms of toxic effects is a benefit of the enzymatic assay. The physicochemical classification of the effects of toxic compounds on bioluminescent 


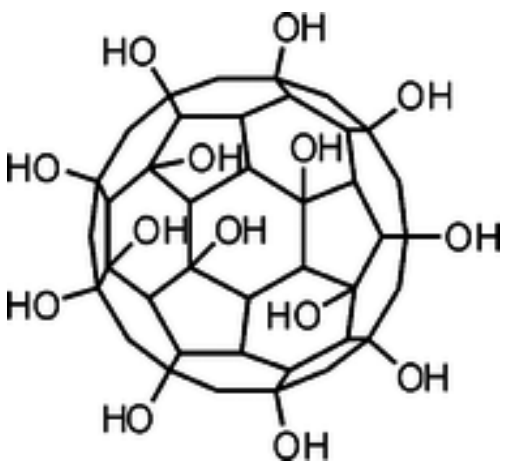

Scheme 1. Hypothetical structure of fullerenol $\mathrm{C}_{60}(\mathrm{OH})_{\mathrm{x}}$.

enzyme system was suggested by Kudryasheva (21) and developed in (22-25).

Enzymatic bioassay can be used for evaluating both general and oxidative toxicities of test samples. Oxidative toxicity is attributed to redox activity of toxic compounds, while the general toxicity (GT) integrates, in a nonadditive way, all the interactions of toxic compounds with components of the bioluminescent enzymatic system, that is redox, hydrophobic and polar interactions. Using the bioluminescent enzymatic assay, the general and oxidative toxicities of organic and inorganic oxidizer' solutions, quinones and polyvalent metals, have been previously studied (25-27). A decrease of both general and oxidative toxicities under exposure to humic substances, the products of natural decomposition of organic matter in soil and bottom sediments, has been previously demonstrated (28-30).

This study develops an application of the enzyme-based bioluminescent assay system for evaluating the toxicity and antioxidant properties of bioactive compounds, fullerenols. A wide range of fullerenol concentrations was tested. The toxicity and detoxifying activities of two fullerenols differed in the number of hydroxyl group and metal substituents, that is $\mathrm{C}_{60} \mathrm{O}_{2-4}(\mathrm{OH})_{20-24}$ and $\mathrm{Fe}_{0.5} \mathrm{C}_{60}(\mathrm{OH})_{\mathrm{x}} \mathrm{O}_{\mathrm{y}}(x+y=40-42)$, have been studied. Inorganic and organic compounds with oxidative propensity (complex salt potassium ferricyanide $\mathrm{K}_{3}\left[\mathrm{Fe}(\mathrm{CN})_{6}\right]$ and 1,4benzoquinone) were used as model toxicants. Potassium ferricyanide was chosen because of its stability in water solutions (in contrast to unclustered iron salts) and monoelectron oxidative transition $\mathrm{Fe}^{3+} / \mathrm{Fe}^{2+}$ (31). The 1,4-benzoquinone was chosen as being a typical representative of the organic oxidizer group. In nature, quinones can appear as a result of an oxidative transformation of various phenols $(32,33)$, that is numerous group of hydroxylated aromatic compounds. They are ranked third in the top list of widespread pollutants (after metal salts and oil products) and are common components of industrial wastewaters. The ability of quinones to deactivate the bacterial enzyme by dislodging flavin, coenzyme of bacterial luciferase, was demonstrated previously in time-resolved fluorescence experiments (34).

The study evaluates fullerenol concentrations which produce a

6 toxic effect (section 3.1) and a decrease of general and oxidative toxicities in solutions (section 3.2). The effects of two fullerenols are compared: $\mathrm{C}_{60} \mathrm{O}_{2-4}(\mathrm{OH})_{20-24}$ and $\mathrm{Fe}_{0.5} \mathrm{C}_{60}(\mathrm{OH})_{\mathrm{x}} \mathrm{O}_{\mathrm{y}}$ $(x+y=40-42)$. The principles of bioluminescent enzyme assay application for evaluating fullerenol's toxic effect and antioxidant activity are summarized in Conclusions.

\section{MATERIALS AND METHODS}

Reagents and equipment. Toxicity of water solutions of model oxidizers $\mathrm{K}_{3}\left[\mathrm{Fe}(\mathrm{CN})_{6}\right]$ (potassium ferricyanide) and 1,4-benzoquinone was assessed using enzymatic assay, that is the preparation based on the coupled enzyme system NADH:FMN-oxidoreductase from Vibrio fischeri $(0.15$ a.u.) and luciferase from Photobacterium leiognathi, $0.5 \mathrm{mg} \mathrm{mL}^{-1}$ (35). The preparation was produced at the Institute of Biophysics SB RAS (Krasnoyarsk, Russia). The chemicals used were as follows: NADH from ICN; FMN and tetradecanal from SERVA, Germany; analytical grade potassium ferricyanide, Khimreactiv, Russia; 1,4-benzoquinone, Aldrich.

The enzymatic assay system includes two coupled reactions:

\section{$\mathrm{NADH}+\mathrm{FMNNADH}:$ FMN-oxidoreductase FMN $\cdot \mathrm{H}^{-}+\mathrm{NAD}^{+}$}

(reaction 1$)$

$\mathrm{FMN} \cdot \mathrm{H}^{-}+\mathrm{RCHO}+\mathrm{O}_{2}$ luciferase $\mathrm{FMN}+\mathrm{RCOO}^{-}+\mathrm{H}_{2} \mathrm{O}+\mathrm{hv}$.

(reaction 2$)$

To construct the enzyme system, $0.1 \mathrm{mg} \mathrm{ml}^{-1}$ enzyme preparation, $5 \cdot 10^{-4} \mathrm{M} \mathrm{FMN}, 4 \cdot 10^{-4} \mathrm{M} \mathrm{NADH}$ and $0.002 \%$ tetradecanal solutions were used. The assay was performed in $0.05 \mathrm{~m}$ phosphate buffer $(\mathrm{pH}$ 6.8) at room temperature.

Fullerenes were synthesized using carbon helium high-frequency arc plasma at the atmospheric pressure $(36,37)$. The fullerene content in carbon soot was about $12.6 \%$. Fullerene mixture was extracted with toluene, and the individual $\mathrm{C}_{60}$ fullerene was separated by liquid chromatography with turbostratic graphite (interplanar distance $3.42 \AA$ ) as a stationary phase and toluene/hexane (4:6) mixture as a mobile phase.

Fullerenol $\mathrm{C}_{60} \mathrm{O}_{2-4}(\mathrm{OH})_{20-24}, \mathrm{~F}_{60}$, was produced by fullerene hydroxylation in concentrated nitric acid followed by the hydrolysis of the polynitrofullerenes $(7,37,38)$. The Fe-containing fullerenol, $\mathrm{F}_{60} \mathrm{Fe}$, was produced from a powder mixture of Fe-containing fullerene soot and acetylacetonate $\mathrm{FeIII}\left(\mathrm{Fe}(\mathrm{acac})_{3}\right)$. The mixture was heated up to spontaneous ignition at $180^{\circ} \mathrm{C}$. The process was continued in the smoldering regime with temperature increase up to $\sim 250^{\circ} \mathrm{C}$. Then, the product was exposed to concentrated nitric acid at $90^{\circ} \mathrm{C}$. The residuum was removed by filtration; red cinnamonic solution was evaporated and treated with distilled water to provide for the hydrolysis of polynitrofullerene to polyhydroxylated fullerene. According to the elemental analysis, the average empirical formula of the fullerenol is $\mathrm{Fe}_{0.5} \mathrm{C}_{60}(\mathrm{OH})_{\mathrm{x}} \mathrm{O}_{\mathrm{y}}(x+y=40-42)$.

The fullerenol preparations were characterized with IR and photoelectron spectroscopies (39).

Experimental data processing. The effects of fullerenols on bioluminescence of enzymatic assay system were evaluated by relative bioluminescent intensity, $I_{\mathrm{F}}^{\mathrm{rel}}$.

$$
I_{\mathrm{F}}^{\mathrm{rel}}=I_{\mathrm{F}} / I_{\mathrm{contr}}
$$

Here, $I_{\text {contr }}$ and $I_{\mathrm{F}}$ are the maximal bioluminescent intensities in the absence and presence of fullerenols, respectively. The values of $I_{\mathrm{F}}^{\text {rel }}<1$ revealed a toxic effect of fullerenols, while the values of $I_{\mathrm{F}}^{\text {rel }} \approx 1$ indicated the absence of such. The effective concentrations of fullerenols that reduce bioluminescent intensity by $50 \%\left(I_{\mathrm{F}}^{\mathrm{rel}}=0.5\right), E C_{50-\mathrm{F}}$, have been determined; they were used to evaluate and compare toxicities of the fullerenols.

$\mathrm{SD}$ values for $I_{\mathrm{F}}^{\mathrm{rel}} \mathrm{did}$ not exceed 0.05 . The data for the $I_{\mathrm{F}}^{\mathrm{rel}}$ calculations were obtained in three parallel experiments with five samplings for all fullerenol and control solutions.

The effects of oxidizers on bioluminescence of enzyme assay system were evaluated by a similar way, that is with relative bioluminescent intensity, $I_{\mathrm{Ox}}^{\mathrm{rel}}$ :

$$
I_{\mathrm{Ox}}^{\mathrm{rel}}=I_{\mathrm{Ox}} / I_{\mathrm{contr}}
$$

Here, $I_{\text {contr }}$ and $I_{\mathrm{Ox}}$ are maximal bioluminescent intensities in the absence and presence of oxidizers, respectively, Fig. 1.

The effective concentrations of the oxidizers, that reduce bioluminescent intensity by $\left.50 \% I_{\mathrm{Ox}}^{\mathrm{rel}}=0.5\right), \mathrm{EC}_{50-\mathrm{Ox}}$, have been determined. 


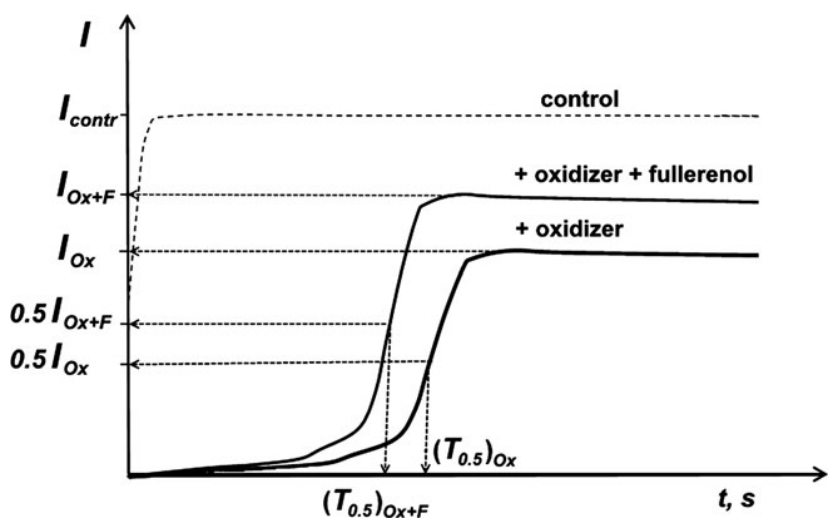

Figure 1. Bioluminescence kinetics in solution of a model oxidizer $(\mathrm{Ox})$ and fullerenol $(F)$.

To characterize the changes of GT under exposure to fullerenols, the detoxification coefficients, $D_{\mathrm{GT}}$, were calculated as follows:

$$
D_{\mathrm{GT}}=I_{\mathrm{Ox}+\mathrm{F}}^{\mathrm{rel}} / I_{\mathrm{Ox}}^{\mathrm{rel}},
$$

where $I_{\mathrm{Ox}}^{\mathrm{rel}}+\mathrm{F}$ and $I_{\mathrm{Ox}}^{\mathrm{rel}}$ are relative bioluminescent intensities in oxidizer solutions at $E C_{50-O x}$, in the presence and absence of fullerenols, respectively. The values of $D_{\mathrm{GT}}$ have been determined at different fullerenol concentrations.

To characterize the oxidative toxicity $(O x T)$, bioluminescent delay period in oxidizer solutions, $\left(T_{0.5}\right)_{\mathrm{Ox}}$, was analyzed, Fig. 1. Changes of $O x T$ under fullerenol exposure were characterized with detoxification coefficients, $D_{\text {OxT: }}$ :

$$
D_{\mathrm{OxT}}=\left(T_{0.5}\right)_{\mathrm{Ox}} /\left(T_{0.5}\right)_{\mathrm{Ox}+\mathrm{F}}
$$

Here, $\left(T_{0.5}\right)_{\mathrm{Ox}+\mathrm{F}}$ and $\left(T_{0.5}\right)_{\mathrm{Ox}}$ are bioluminescence delay periods in oxidizer solutions in the presence and absence of fullerenols, respectively, Fig. 1. The values of $D_{\mathrm{OxT}}$ have been determined at different fullerenol concentrations.

The values of $D_{\mathrm{GT}}>1$ and $D_{\mathrm{OxT}}>1$ revealed a decrease of GT and $O x T$ in oxidizer solutions under the exposure to fullerenols. The values of $D_{\mathrm{GT}} \approx 1$ and $D_{\mathrm{OxT}} \approx 1$ revealed the absence of the fullerenol effects.

The values of SD for $D_{\mathrm{GT}}$ and $D_{\mathrm{OxT}}$ did not exceed 0.1 . The data for the calculations of $D_{\mathrm{GT}}$ or $D_{\mathrm{OxT}}$ were obtained in five parallel experiments with 4-5 samplings for all fullerenol and control solutions.

\section{RESULTS AND DISCUSSION}

\section{Toxicity of fullerenol solutions}

Figure 2 presents the dependence of bioluminescent intensity $I_{\mathrm{F}}^{\mathrm{rel}}$ of the enzymatic assay system on the concentrations of

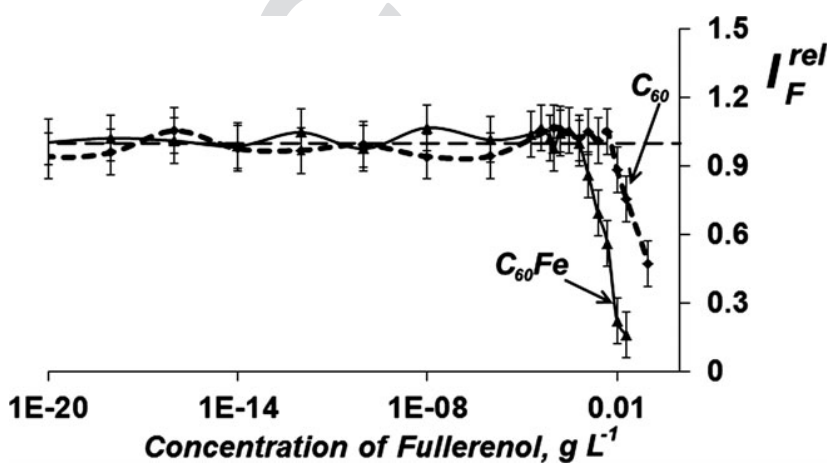

Figure 2. Bioluminescent intensity $I_{\mathrm{F}}^{\text {rel }}$ of enzymatic assay system at different concentrations of $\mathrm{F}_{60}$ and $\mathrm{F}_{60} \mathrm{Fe}$. fullerenols. Values of $E C_{50-\mathrm{F}}$ have been determined; they appeared to be about 0.1 and $0.005 \mathrm{~g} \mathrm{~L}^{-1}$ for $\mathrm{F}_{60}$ and $\mathrm{F}_{60} \mathrm{Fe}$, respectively. These values indicate a higher toxicity of $\mathrm{F}_{60} \mathrm{Fe}$. The reasons for the higher toxicity can be related to the presence of iron atoms in the fullerenol structure and the reduction of fullerenol $\pi$-system $(3,4,7,8)$.

The result demonstrates that the bioluminescent enzyme system is applicable for evaluating the toxicity of fullerenols of different structure.

\section{Antioxidant activity of fullerenols}

The bioluminescent intensity was measured in the solutions of model oxidizers 1,4-benzoquinone and potassium ferricyanide in the absence and presence of fullerenols $\mathrm{F}_{60}$ and $\mathrm{F}_{60} \mathrm{Fe}$.

The values of $\mathrm{EC}_{50-\mathrm{Ox}}$ were preliminary calculated as $10^{-5} \mathrm{M}$ and $2 \cdot 10^{-5} \mathrm{M}$ for 1 ,4-benzoquinone and potassium ferricyanide, respectively. These concentrations were applied to monitor the changes of GT under exposure to fullerenols and calculate $D_{\mathrm{GT}}$ values.

Lower concentrations of fullerenols which do not produce toxic effects $\left(<5 \cdot 10^{-3} \mathrm{~g} \mathrm{~L}^{-1}\right.$ for $\mathrm{F}_{60}$ and $<10^{-3} \mathrm{~g} \mathrm{~L}^{-1}$ for $\mathrm{F}_{60} \mathrm{Fe}$, Fig. 2) have been chosen to monitor toxicity of the solutions. The concentrations of fullerenols varied as shown in Figs. 3 and 4. Detoxification coefficients $D_{\mathrm{GT}}$ and $D_{\mathrm{OxT}}$ have been calculated according to Eqs. (2) and (3), respectively. The results are shown in Figs. 3 and 4.

Figure 3 presents dependencies of detoxification coefficients $D_{\mathrm{GT}}$ and $D_{\mathrm{OxT}}$ on fullerenol concentrations in the solutions of
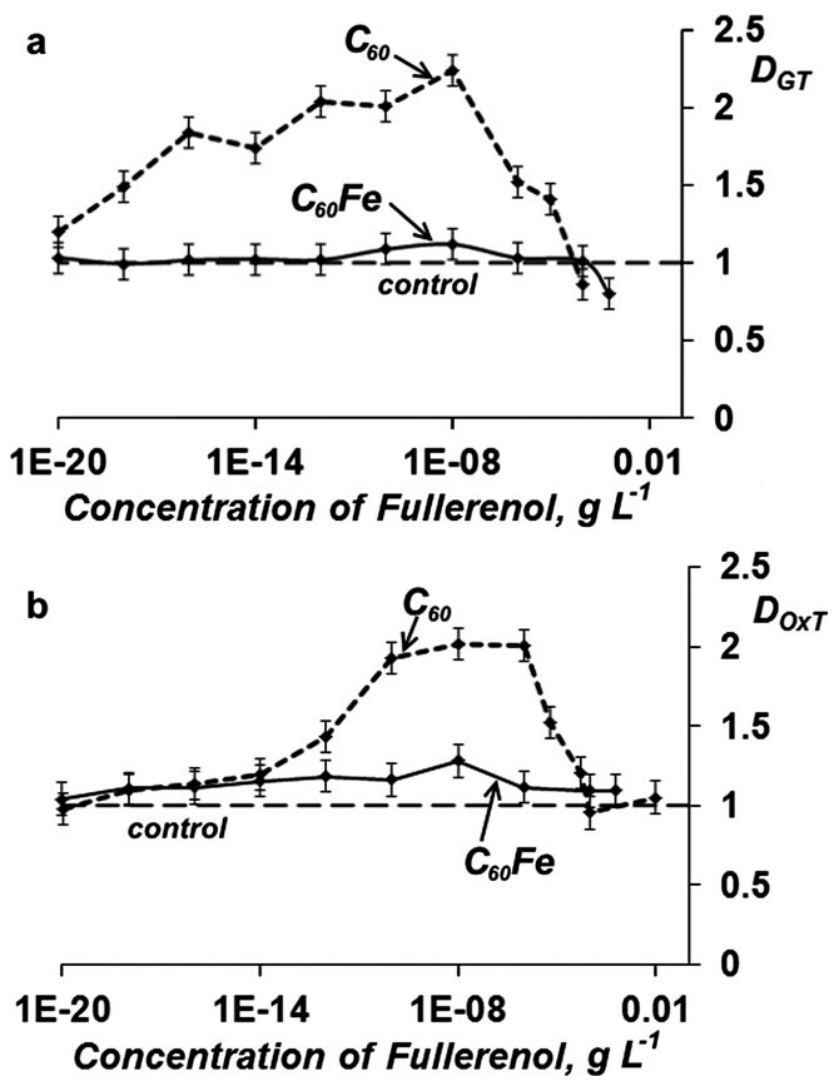

Figure 3. Detoxification coefficients $D_{\mathrm{GT}}$ (a) and $D_{\mathrm{OxT}}$ (b) vs. concentration of fullerenols $\mathrm{F}_{60}$ and $\mathrm{F}_{60} \mathrm{Fe}$ in solutions of 1,4-benzoquinone $\left(10^{-5} \mathrm{M}\right)$ 
a

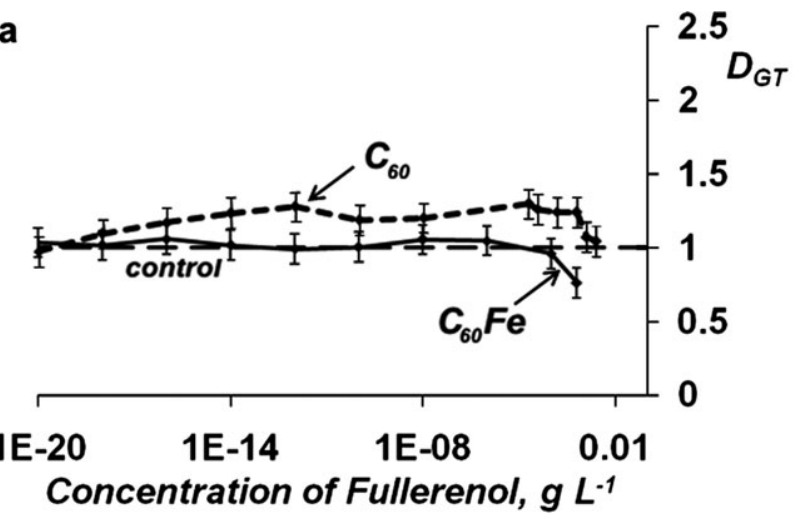

b

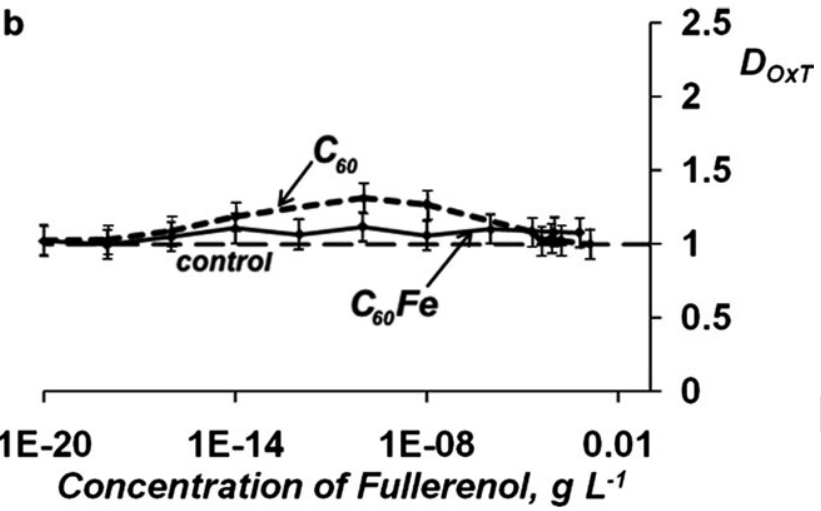

Figure 4. Detoxification coefficients $D_{\mathrm{GT}}$ (a) and $D_{\mathrm{OxT}}$ (b) vs. concentration of fullerenols $\mathrm{F}_{60}$ and $\mathrm{F}_{60} \mathrm{Fe}$ in solutions of potassium ferricyanide $\left(2 \cdot 10^{-5} \mathrm{M}\right)$.

the organic oxidizer, 1,4-benzoquinone. The antioxidant effect of $\mathrm{F}_{60}\left(D_{\mathrm{GT}}>1, D_{\mathrm{OxT}}>1\right)$ in a wide range of fullerenol concentrations is evident from Fig. $3 \mathrm{a}, \mathrm{b}$, while fullerenol $\mathrm{F}_{60} \mathrm{Fe}$ does not show a toxicity decrease as values of $D_{\mathrm{GT}}$ and $D_{\mathrm{OxT}}$ were found to be close to 1 (Fig. 3a, b).

Figure 4 demonstrates the effects of the fullerenols in solutions of inorganic oxidizer, potassium ferricyanide: The antioxidant effect of $\mathrm{F}_{60}\left(D_{\mathrm{GT}}>1, D_{\mathrm{OxT}}>1\right)$ is evident from this figure, while fullerenol $\mathrm{F}_{60} \mathrm{Fe}$ does not demonstrate a toxicity decrease (the values of $D_{\mathrm{GT}}$ and $D_{\mathrm{OxT}}$ were close to 1 ). It is noticeable that the detoxification coefficients in the solutions of the inorganic oxidizer exposed to $F_{60}$ (Fig. 4) appeared to be lower than those in organic oxidizer solutions (Fig. 3).

In (40), a similar effect was explained through the involvement of hydrophobic interactions in the detoxification mechanism. In that paper, the antioxidant properties of fullerenols ascribed to their catalytic activity in the enzymatic reactions. Fullerenol' antioxidant effect for bacterial cells is more complex; it was discussed (40) in terms of hormesis phenomenon. In this context, it should be stressed that antioxidant effects in vivo are sometimes more intricate than in vitro. For instance, chain-breaking antioxidants may exhibit considerable activity in living organisms despite their rather moderate radical-scavenging efficiency in model oxidation processes (41).

\section{CONCLUSION}

The study demonstrates a high potential of the bioluminescent enzymatic assay for evaluating the toxicity and antioxidant activity of bioactive compounds. The assay enables studying the toxic and antioxidant effects at the level of nanosized structures (enzymes, low-molecular components of enzymatic reactions and bioactive compounds). The assay provides for the evaluation of both oxidative toxicity $(O x T)$ and GT. These toxicity types consider redox processes (for $O x T$ ) and nonadditive integral combination of redox-, hydrophobic- and polar-dependent interactions (for GT).

Two fullerenols of different structure were chosen here as model bioactive species. The results show different antioxidant efficiency and toxicity of these fullerenols, supporting, by this, applicability of the assay.

The procedure steps for evaluating the antioxidant and toxic effect of bioactive compounds are described below. Fullerenols (F) are considered here as an example of bioactive compounds.

1 Registration of bioluminescent kinetics (Fig. 1) for enzyme preparation (control-1); enzyme preparation + oxidizer (control-2); enzyme preparation + oxidizer + fullerenol (tested sample). Evaluation of maximal bioluminescent intensities $I_{\text {contr }}, I_{\mathrm{Ox}}$ and $I_{\mathrm{Ox}+\mathrm{F}}$, as well as induction periods in control-2 $\left(T_{0.5}\right)_{\mathrm{Ox}}$ and tested samples $\left(T_{0.5}\right)_{\mathrm{Ox}+\mathrm{F}}$, Fig. 1.

2 Calculation of $I_{\mathrm{F}}^{\mathrm{rel}}, I_{\mathrm{Ox}}^{\mathrm{rel}}$ and $I_{\mathrm{Ox}+\mathrm{F}}^{\mathrm{ree}}$ using Eqs. (1) and (1a). Statistical treatment.

3 Evaluation of effective concentrations of fullerenols, $\mathrm{EC}_{50-\mathrm{F}}$. Comparison of $\mathrm{EC}_{50-\mathrm{F}}$ of fullerenols. A conclusion on the difference in the toxicities of the fullerenols.

4 Calculation of $D_{\mathrm{GT}}$ and $D_{\mathrm{OxT}}$ according to Eqs. (2) and (3). Statistical treatment. A conclusion on the antioxidant activity of fullerenols: Values of $D_{\mathrm{GT}}, D_{\mathrm{OxT}}>1$ indicate antioxidant activity. A conclusion on the difference in the antioxidant activity of the fullerenols.

Acknowledgements-The work was supported by the Russian Foundation for Basic Research, Grants 15-03-06786 and 15-43-04377-sibir; the state budget allocated to the fundamental research at the Russian Academy of Sciences (project 01201351504).

\section{REFERENCES}

1. Foley, S., C. Crowley, M. Smaihi, C. Bonfils, B. F. Erlanger, P. Seta and C. Larroque (2002) Cellular localization of a water-soluble fullerene derivative. Biochem. Biophys. Res. Commun. 294, 116-119.

2. Grebowski, J., A. Krokosz and M. Puchala (2013) Fullerenol $\mathrm{C}_{60}(\mathrm{OH})_{36}$ could associate to band 3 protein of human erythrocyte membranes. Biochim. Biophys. Acta 1828, 2007-2014.

3. Eropkin, M. Y., E. Y., Melenevskaya, K. V. Nasonova, T. S. Bryazzhikova, E. M. Eropkina, D. Baibus and O. I. Kiselev (2013) Synthesis and biological activity of fullerenols with various contents of hydroxyl groups. Pharm. Chem. J. 47, 87-91.

4. Grebowski, J., P. Kazmierska and A. Krokosz (2013) Fullerenols as a new therapeutic approach in nanomedicine. Biomed. Res. Int. 2013, $1-9$.

5. Wang, Z., S. Wang, Z.-H. Lu and X. Gao (2015) Syntheses, structures and antioxidant activities of fullerenols: knowledge learned at the atomistic level. J. Clust. Sci. 26, 375-388.

6. Jiao, F., Y. Liu, Y. Qu, W. Li, G. Zhou, C. Ge, Y. Li, B. Sun and Ch. Chen (2010) Studies on anti-tumor and antimetastatic activities of fullerenol in a mouse breast cancer model. Carbon 48, 22312243.

7. Goncharova, E. A., V. G. Isakova, E. V. Tomashevich and G. N. Churilov (2009) Obtaining of water-soluble polyhydroxylated fullerenols with iron nanoparticles as catalyzers. Vestnik SibGAU. 22, 9093. (In Russian).

8. Mirkov, S. M., A. N. Djordjevic, N. L. Andric, S. A. Andric, T. S. Kostic, G. M. Bogdanovic, M. B. Vojinovic-Miloradov and R. Z. Kovacevic (2004) Nitric oxide-scavenging activity of polyhydroxylated fullerenol, $\mathrm{C}_{60}(\mathrm{OH})_{24}$. Nitric Oxide 11, 201-207. 
9. Djordjevic, A., B. Srdjenovic, M. Seke, D. Petrovic, R. Injac and J. Mrdjanovic (2015) Review of synthesis and antioxidant potential of fullerenol nanoparticles. J. Nanomater. 2015, 1-15.

10. Djordjevic, A., J. M. Canadanovic-Brunet, M. Vojinovic-Miloradov and G. Bogdanovic (2004) Antioxidant properties and hypothetic radical mechanism of fullerenol $\mathrm{C}_{60}(\mathrm{OH})_{24}$. Oxid. Commun. 27, 806-812.

11. Bulich, A. A. and D. L. Isenberg (1981) Use of the luminescent bacterial system for rapid assessment of aquatic toxicity. ISA Trans. 20, 29-33.

12. Fedorova, E., N. Kudryasheva, A. Kuznetsov, O. Mogil'naya and D. Stom (2007) Bioluminescent monitoring of detoxification processes: activity of humic substances in quinone solutions. J. Photochem. Photobiol., B 88, 131-136.

13. Girotti, S., E. N. Ferri, M. G. Fumo and E. Maiolini (2008) Monitoring of environmental pollutants by bioluminescent bacteria. Anal. Chim. Acta 608, 2-29.

14. Kudryasheva, N. S., V. A. Kratasyuk, E. N. Esimbekova, E. V. Vetrova, E. V. Nemtseva and I. Y. Kudinova (1998) Development of bioluminescent bioindicators for analyses of environment pollution. Field Anal. Chem. Tech. 2, 277-280.

15. Roda, A., P. Pasini, M. Mirasoni, E. Michchelini and M. Guardigli (2004) Biotechnological application of bioluminescence and chemiluminescence. Trends Biotechnol. 22, 295-303.

16. Kudryasheva, N. S. and T. V. Rozhko (2015) Effect of low-dose ionizing radiation on luminous marine bacteria: radiation hormesis and toxicity. J. Environ. Radioact. 142, 68-77.

17. Rozhko, T. V., N. S. Kudryasheva, A. M. Kuznetsov, G. A. Vydryakova, L. G. Bondareva and A. Ya. Bolsunovsky (2007) Effect of low-level $\alpha$-radiation on bioluminescent assay systems of various complexity. Photochem. Photobiol. Sci. 6, 67-70.

18. Selivanova, M. A., O. A. Mogilnaya, G. A. Badun, G. A. Vydryakova, A. M. Kuznetsov and N. S. Kudryasheva (2013) Effect of tritium on luminous marine bacteria and enzyme reactions. J. Environ. Radioact. 120, 19-25.

19. Esimbekova, E. N., A. M. Kondik and V. A. Kratasyuk (2013) Bioluminescent enzymatic rapid assay of water integral toxicity. Environ. Monit. Assess. 185, 5909-5916.

20. Kratasyuk, V. A. and E. N. Esimbekova (2015) Applications of luminous bacteria enzymes in toxicology. Comb. Chem. High Throughput Screen. 18, 952-959.

21. Kudryasheva, N. S. (2006) Bioluminescence and exogenous compounds: physico-chemical basis for bioluminescence assay. J. Photochem. Photobiol., B 83, 77-86.

22. Kirillova, T. N. and N. S. Kudryasheva (2007) Effect of heavy atom in bioluminescent reactions. Anal. Bioanal. Chem. 387, 2009-2016.

23. Kirillova, T. N., M. A. Gerasimova, E. V. Nemtseva and N. S Kudryasheva (2011) Effect of halogenated fluorescent compounds on bioluminescent reactions. Anal. Bioanal. Chem. 400, 343-351.

24. Nemtseva, E. V. and N. S. Kudryasheva (2007) The mechanism of electronic excitation in bacterial bioluminescent reaction. Usp. Khim. 76, 101-112.

25. Vetrova, E. V., N. S. Kudryasheva and V. A. Kratasyuk (2007) Redox compounds influence on the NAD(P)H:FMN-oxidoreductase-luciferase bioluminescent system. Photochem. Photobiol. Sci. 6, 35-40.

26. Kudryasheva, N., E. Vetrova, A. Kuznetsov, V. Kratasyuk and D. Stom (2002) Bioluminescent assays: effects of quinones and phenols. Ecotoxicol. Environ. Saf. 53, 221-225.
27. Tarasova, A. S., D. I. Stom and N. S. Kudryasheva (2011) Effect of humic substances on toxicity of inorganic oxidizer bioluminescent monitoring. Environ. Toxicol. Chem. 30, 1013-1017.

28. Kudryasheva, N. S. and A. S. Tarasova (2015) Pollutant toxicity and detoxification by humic substances: mechanisms and quantitative assessment via luminescent biomonitoring. Environ. Sci. Pollut. Res. Int. 22, 155-167.

29. Tarasova, A. S., D. I. Stom and N. S. Kudryasheva (2015) Antioxidant activity of humic substances via bioluminescent monitoring in vitro. Environ. Monit. Assess. 187, 89.

30. Tarasova, A. S., S. L. Kislan, E. S. Fedorova, A. M. Kuznetsov, O. A. Mogilnaya, D. I. Stom and N. S. Kudryasheva (2012) Bioluminescence as a tool for studying detoxification processes in metal salt solutions involving humic substances. J. Photochem. Photobiol., B 117, 164-170.

31. Katafias, A., O. Impert and P. Kit (2008) Hydrogen peroxide as a reductant of hexacyanoferrate (III) in alkaline solutions: kinetic studies. Transition Met. Chem. 33, 1041-1046.

32. Esguerra, K. V. N., Ya. Fall, L. Petitjean and J.-P. Lumb (2014) Controlling the catalytic aerobic oxidation of phenols. J. Am. Chem. Soc. 136, 7662-7668.

33. Kamnev, A. A., R. L. Dykman, K. Kovács, A. N. Pankratov, A. V. Tugarova, Z. Homonnay and E. Kuzmann (2014) Redox interactions between structurally different alkylresorcinols and iron(III) in aqueous media: frozen-solution ${ }^{57} \mathrm{Fe}$ Mössbauer spectroscopic studies, redox kinetics and quantum chemical evaluation of the alkylresorcinol reactivities. Struct. Chem. 25, 649-657.

34. Vetrova, E. V., N. S. Kudryasheva, A. Visser and A. van Hoek (2005) Characteristics of endogenous flavin fluorescence of Photobacterium leiognathi luciferase and Vibrio fischeri NAD(P)H:FMNoxidoreductase. Luminescence 20, 205-209.

35. Kuznetsov, A. M., E. K. Rodicheva and E. V. Shilova (1996) Bioassay based on lyophilized bacteria. Biotekhnologiya 9, 57-61. (in Russian).

36. Churilov, G. N. (2008) Synthesis of fullerenes and other nanomaterials in arc discharge. Fuller. Nanotub. Car. N. 16, 395-403.

37. Churilov, G. N., W. Kratschmer, I. V. Osipova, G. A. Glushenko, N. G. Vnukova, A. L. Kolonenko and A. I. Dudnik (2013) Synthesis of fullerenes in a high-frequency arc plasma under elevated helium pressure. Carbon 62, 389-392.

38. Isakova, V. G., E. A. Goncharova, O. A. Bayukov and G. N. Churilov (2011) Hydroxylation of fullerenes modified with iron nanoparticles. Russ. J. Appl. Chem. 84, 1093-1097.

39. Li, J., M. Zhang, B. Sun, G. Xing, Y. Song, H. Guo, Ya. Chang, Y. Ge and Y. Zhao (2012) Separation and purification of fullerenols for improved biocompatibility. Carbon 50, 460-469.

40. Sachkova, A. S., E. S. Kovel, G. N. Churilov, I. A. Dubinina, A. A. Vorobeva and N. S. Kudryasheva (2016) Fullerenols as bioactive compounds: antioxidant activity of fullerenols via luminescent biomonitoring. Biochim. Biophys. Acta, Submitted.

41. Slavova-Kazakova, A. K., S. E. Angelova, T. L. Veprintsev, P Denev, D. Fabbri, M. A. Dettori, M. Kratchanova, V. V. Naumov, A. V. Trofimov, R. F. Vasil'ev, G. Delogu and V. D. Kancheva (2015) Antioxidant potential of curcumin-related compounds studied by chemiluminescence kinetics, chain-breaking efficiencies, scavenging activity (ORAC) and DFT calculations. Beilstein J. Org. Chem. 11, 1398-1411. 